\title{
MEDAN MAGNET DI SEKITAR REL KERETA API
}

\author{
Ah. Sulhan Fauzi ${ }^{1}$, Am. Mufarrih ${ }^{2}$. \\ ${ }^{1,2}$ Teknik Mesin, Universitas Nusantara PGRI Kediri \\ E-mail: ${ }^{1}$ sulhanfauzi@ unpkediri.ac.id
}

\begin{abstract}
Abstrak
Penelitian ini dilakukan untuk mengetahui apakah benar ada medan magnet di sekitar rel saat kereta api sedang melintas. Beberapa kecelakaan yang melibatkan kereta api dan mobil di atas perlintasan kereta api diperkirakan disebabkan karena medan megnet ini. Belum ada penelitian atau data resmi dari kepolisian yang menjelaskan penyebab tiba-tiba mesin kendaraan bermotor tersebut mati saat melintas di atas rel yang ada kereta apinya sedang berjalan. Pendapat lain juga muncul dari kejadian ini, yaitu karena sopir atau pengendara kendaraan tersebut gugup saat melihat kereta yang melintas waktu lewat di atas rel, sehingga menjadi kehilangan fokus saat mengemudi sehingga menyebabkan mesin kendaraannya mati. Data hasil pengukuran medan magnet menunjukkan bahwa nilai medan magnet di sekitar rel kereta api saat kereta api melintas rata-rata $47,73 \mu \mathrm{T}$, dengan nilai medan magnet terendah $22,46 \mu \mathrm{T}$ dan nilai tertingginya $82,06 \mu \mathrm{T}$. Nilai tersebut tidak berbeda jauh dengan nilai medan magnet bumi yaitu antara $25-65 \mu \mathrm{T}$.
\end{abstract}

Kata Kunci: kereta api, medan magnet, rel, kereta api.

\begin{abstract}
This research was conducted to find out whether there is a magnetic field around the rail when the train is passing. Some accidents involving trains and cars on railroad crossings are thought to be due to this megnet field. There has been no official research or data from the police that explains the sudden cause of the engine of the motor vehicle to die while crossing on the tracks where the train is running. Another opinion also arises from this incident, namely because the driver or driver of the vehicle is nervous when he sees a passing train passing on the rail, thus losing focus while driving, causing the vehicle's engine to die. The magnetic field measurements data's showed that the magnetic field values around the railroad tracks when the train crossed averaged $47.73 \mu T$, with the highest magnetic field values $82.06 \mu T$ and the lowest $22.46 \mu T$. This value does not greatly differ from the value of the earth's magnetic field, which is between 25-65 $\mu$ T.
\end{abstract}

Keywords: magnetic field, rail, train

\section{PENDAHULUAN}

Medan magnetik didefinisikan sebagai ruangan di sekitar magnet yang masih terpengaruh gaya magnetik. Seperti pada gaya listrik, kita menganggap gaya magnetik tersebut dipindahkan oleh sesuatu, yaitu medan magnetik. Muatan yang bergerak menghasilkan medan magnetik dan medan ini selanjutnya, memberikan

Diterima: 04 Juli 2019; direvisi terakhir 22 Juli 2019; diterbitkan 25 Juli 2019 
suatu gaya pada muatan bergerak lainnya. Karena muatan bergerak menghasilkan arus listrik, interaksi magnetik dapat juga dianggap sebagai interaksi di antara dua arus. Kuat dan arah medan magnetik dapat juga dinyatakan oleh garis gaya magnetik. Jumlah garis gaya per satuan penampang melintang adalah ukuran kuat medan magnetik.

Pemagnetan suatu bahan oleh medan magnet luar disebut induksi. Induksi magnetik sering didefinisikan sebagai timbulnya medan magnetik akibat arus listrik yang mengalir dalam suatu penghantar. Oersted menemukan bahwa arus listrik menghasilkan medan magnetik [1, 2]. Selanjutnya, secara teoritis Laplace (17491827) menyatakan bahwa kuat medan magnetik atau induksi magnetik di sekitar arus listrik berbanding lurus dengan kuat arus listrik,panjang kawat penghantar dan berbanding terbalik dengan kuadrat jarak suatu titik dari kawat penghantar tersebut.

Besarnya medan magnet yang dihasilkan dari kawat lurus beraliran listrik dapat dihitung dengan persamaan Biot-Savart [1, 2]:

$$
B=\frac{\mu_{o}}{2 \pi} \frac{I}{a}
$$

Dengan:

$B=$ kuat medan magnet $(\mathrm{T})$,

$\mu_{o}=4 \pi \times 10^{-7}\left(\mathrm{~Wb} \cdot \mathrm{A}^{-1} \cdot \mathrm{m}^{-1}\right)$,

$I=\operatorname{arus} \operatorname{listrik}(\mathrm{A})$,

$a=$ jarak titik dengan kawat (m).

Gesekan antara rel dan roda kereta api yang terbuat dari besi diasumsikan dapat menghasilkan muatan listrik yang bergerak sehingga menimbulkan arus listrik ( $I)$, sehingga menimbulkan medan magnet (B) sesuai dengan jarak (a) disekitarnya [3].

\section{METODE PENELITIAN}

Penelitian dilakukan dalam bentuk kuantitatif dengan pengukuran nilai medan magnet secara langsung menggunakan, Tesla Meter yang diletakkan di tengah rel saat kereta api melintas menggunakan mode recording. Pengambilan data dilakukan di 3 tempat perlintasan kereta api di sekitar kabupaten dan kota Kediri 
dengan pertimbangan perbedaan kecepatan kereta api, yaitu kecepatan rendah, kecepatan sedang dan tempat ketiga untuk kecepatan tinggi. Pengukuran dilakukan selama 3 menit atau 180 detik, dimulai kira-kira 1 menit sebelum kereta api melintas.

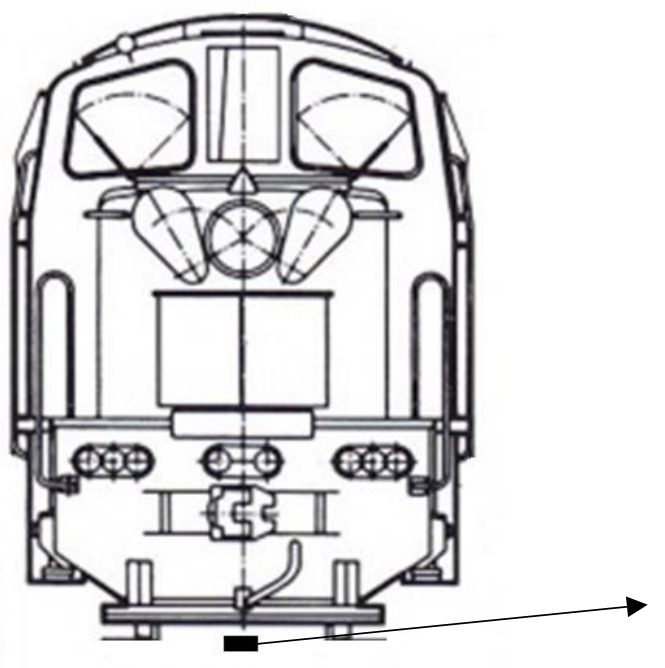

- Tesla Meter diaktifkan pada mode record selama 3 menit.

- Tesla Meter diletakkan di tengah-tengah rel 1 menit sebelum kereta api melintas.

- Setelah kereta melintas Tesla Meter diambil dan diunggah data hasil pengukurannya.

Tesla Meter

Gambar 1. Metode penelitian

\section{HASIL DAN PEMBAHASAN}

Hasil pengukuran yang diperoleh dari Tesla meter berupa nilai-nilai medan magnet tiap detik. Data hasil pengukuran medan magnet dibagi menjadi tiga kelompok yaitu, pertama data medan magnet saat kecepatan kereta api rendah, kedua data saat kereta api berkecepatan sedang dan ketiga data saat kereta api berkecepatan tinggi.

Hasil pengukuran besarnya medan magnet tersebut kemudian dijadikan grafikgrafik yang diperlihatkan pada gambar 1,2 dan 3. Data grafik menunjukkan nilai medan magnet yang fluktuatif, naik turun secara tidak teratur, terutama pada grafik ketiga untuk nilai medan magnet saat kereta api berkecepatan tinggi. 


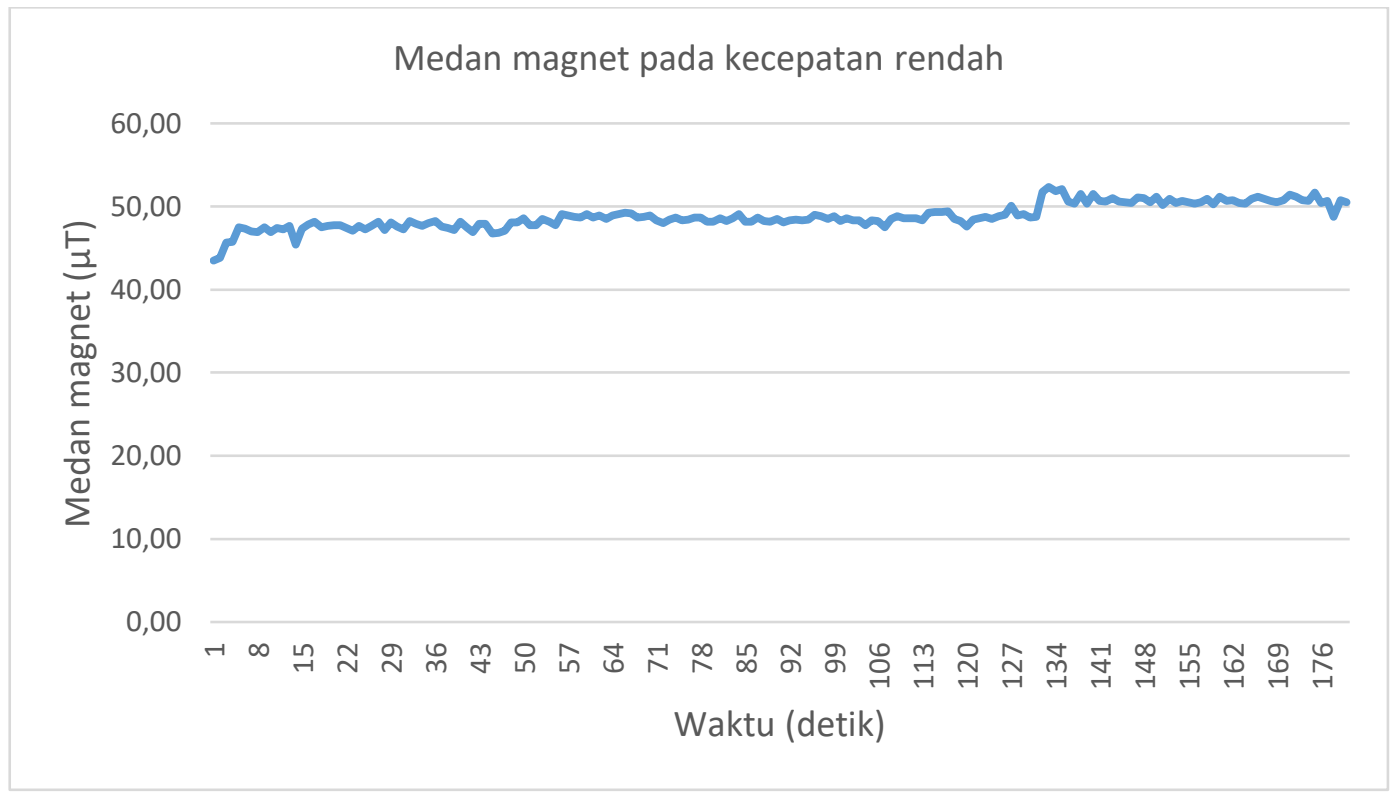

Gambar 2. Medan magnet saat kereta api berkecepatan rendah

Grafik pertama, adalah data medan magnet saat kereta berkecepatan rendah, diambil saat kereta akan berangkat dari Stasiun. Terlihat grafiknya tidak mengalami kenaikan atau penurunan yang berarti, meski tampak terjadi kenaikan. Nilai terendahnya adalah $43,49 \mu \mathrm{T}$, dan nilai tertingginya adalah $51,87 \mu \mathrm{T}$. Rata-rata nilai medan magnetnya adalah $48,81 \mu \mathrm{T}$.

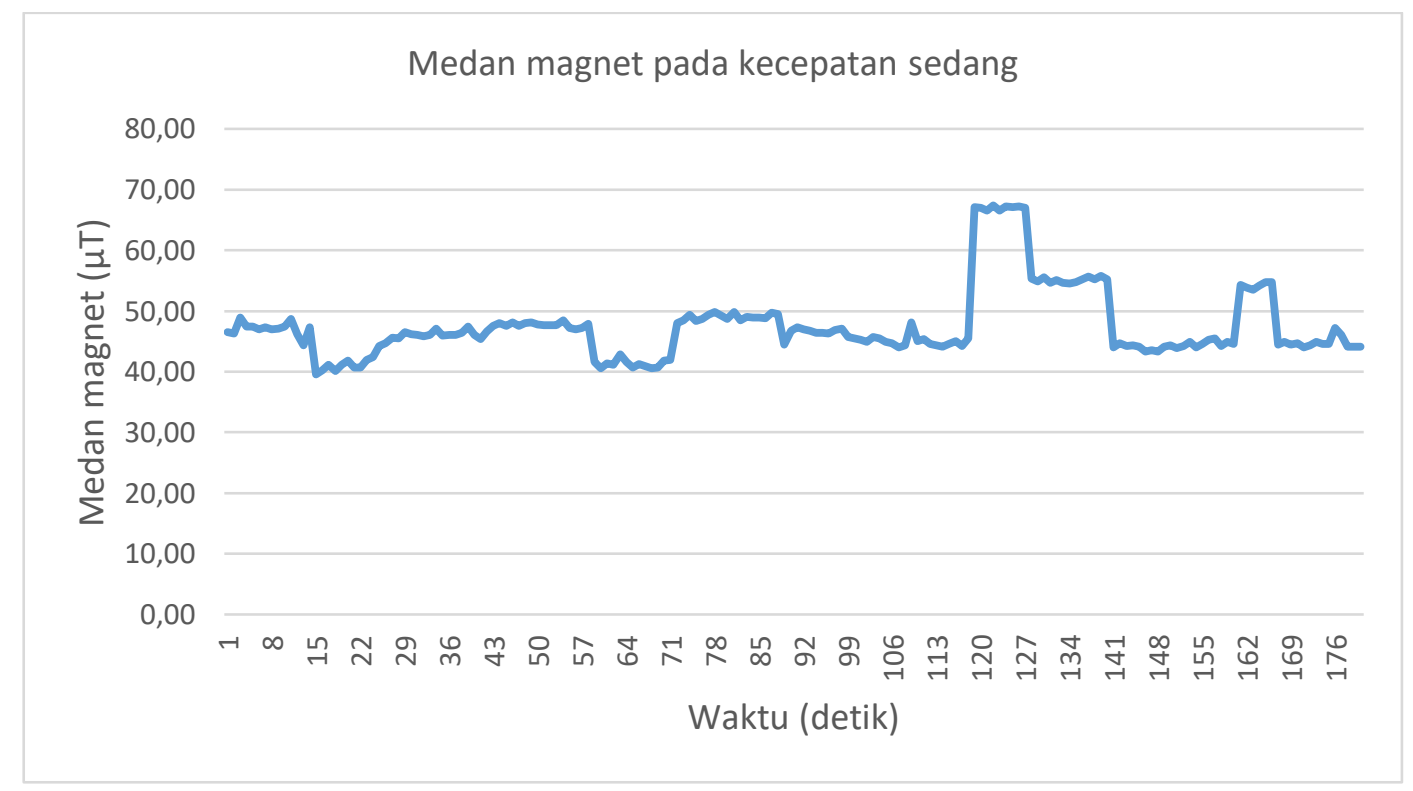

Gambar 3. Medan magnet saat kereta api berkecepatan sedang 
Pada grafik kedua terlihat rentang nilai medan magnet terendah dan tertingginya lebih besar dari grafik pertama. Saat kereta api berkecepatan sedang ini, nilai medan magnet terendahnya adalah 40,19 $\mu \mathrm{T}$ dan nilai medan magnet tertingginya adalah $66,57 \mu \mathrm{T}$. Nilai rata-rata medan magnetnya adalah $47,18 \mu \mathrm{T}$.

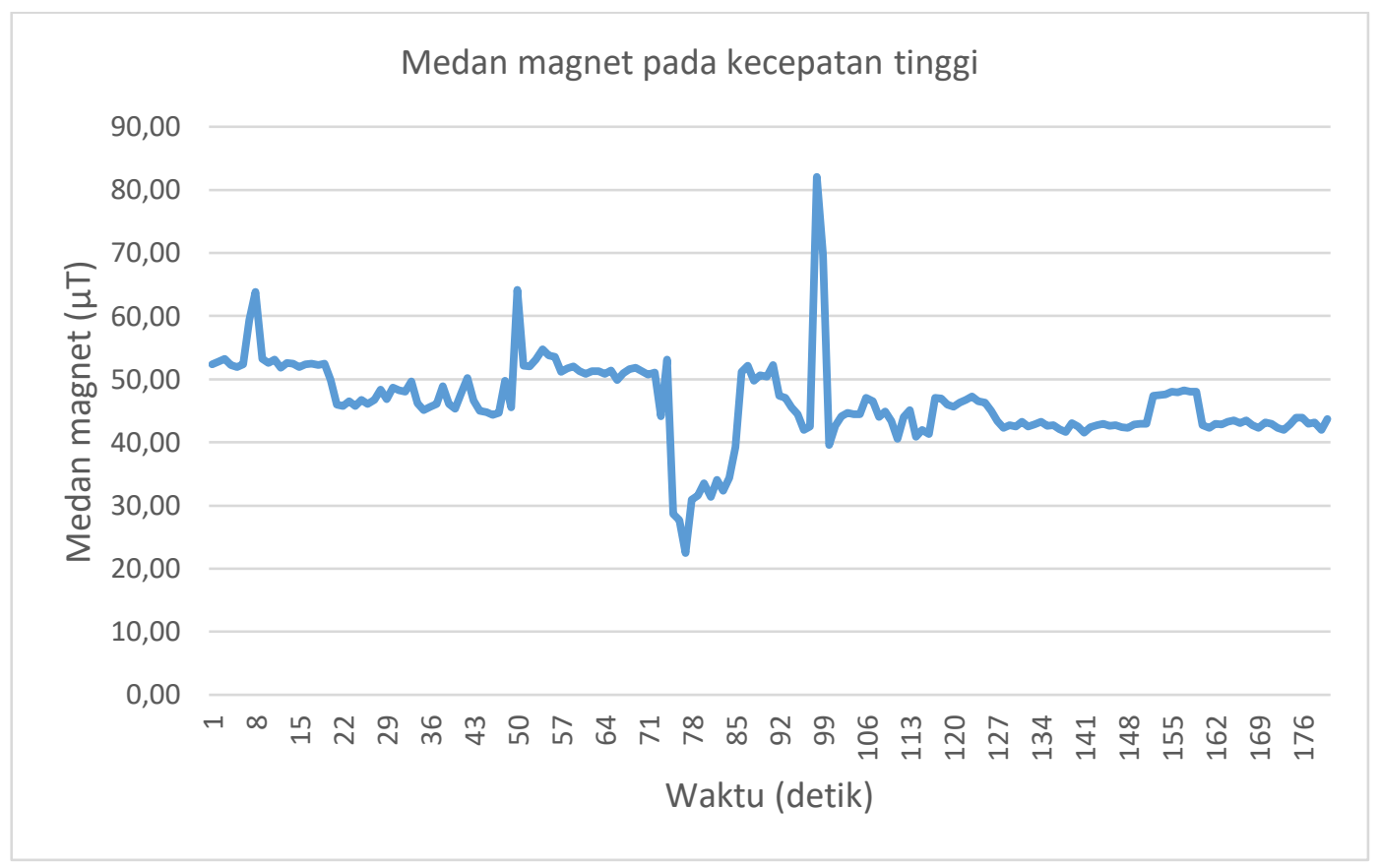

Gambar 4. Medan magnet saat kereta api berkecepatan tinggi

Pada grafik ketiga terlihat fluktuasi nilai medan magnetnya lebih besar dari kedua grafik yang pertama. Saat kereta api berkecepatan tinggi ini, nilai medan magnet terendahnya adalah $22,46 \mu \mathrm{T}$ dan nilai medan magnet tertingginya adalah $82,06 \mu \mathrm{T}$ dan rata-rata medan magnetnya adalah $47,20 \mu \mathrm{T}$.

Pada saat kereta api berkecepatan rendah, fluktuasi nilai medan magnetnya terlihat paling rendah yaitu hanya berselisih $8,38 \mu \mathrm{T}$, sedangkan fluktuasi tertinggi terlihat pada data ketiga saat kereta api berkecepatan tinggi, yaitu 59,6 $\mu \mathrm{T}$. Fluktuasi nilai medan magnet ini menunjukkan bahwa gesekan antara roda dan rel kereta api tersebut mempengaruhi nilai medan magnet bumi di sekitarnya. Data hasil pengukuran medan magnet menunjukkan bahwa semakin cepat gesekan antara roda dan rel kereta api semakin mempengaruhi besarnya medan magnet bumi di sekitar rel sehingga mengalami fluktuasi yang cukup tinggi. Kemungkinan juga karena posisi alat yang bergetar saat kereta api melintas sehingga membuat medan magnet di sekitar alat ukur mengalami perubahan. 
Penelitian-penelitian sebelumnya menunjukkan nilai medan magnet bumi yang bervariasi dari $25 \mu \mathrm{T}$ hingga $65 \mu \mathrm{T}$ [4]. Gustara, 2016, membuat sensor solenoida yang berhasil digunakan untuk mengukur medan magnet di sekitar rel kereta api, yaitu sekitar 0,384 Gauss sampai 5,380 Gauss, atau sekitar 38,4 $\mu \mathrm{T}$ sampai 538,0 $\mu \mathrm{T}$ [5]. Medan magnet di sekitar rel juga terukur sebesar $40 \mu \mathrm{T}$ sampai $150 \mu \mathrm{T}$ dengan pengukuran menggunakan metode calculated dynamic power spectral density [6]. Anomali medan magnet juga terjadi sebesar 100-450 nT [7]. Tercatat juga badai besar geomagnet dengan nilai perubahan berkisar 71-20 nT [8]. Beberapa penelitian lain juga menyebutkan bahwa nilai medan magnet bumi ternyata mengalami penurunan, menurut John Tarduno, dkk., kekuatan medan magnet bumi melemah selama kurang lebih 160 tahun terakhir [9]. Maxwell Brown juga menyatakan bahwa nilai medan magnet bumi tidak mungkin sama setiap saatnya [10].

\section{KESIMPULAN}

Berdasarkan data-data hasil penelitian dapat disimpulkan bahwa tidak timbul medan magnet akibat gesekan antara roda dan rel kereta api saat kereta api melintas. Yang terjadi adalah perubahan medan magnet bumi di sekitar rel saat kereta api melintas, yaitu berubah dari 22,46 $\mu \mathrm{T}$ hingga $82,06 \mu \mathrm{T}$.

\section{DAFTAR PUSTAKA}

[1] Alonso, Finn. "Fundamental University Physics". New York: Addison Wesley. 1990.

[2] Halliday dan Resnick. "Fisika Jilid I, terjemahan Pantur Silaban dan Erwin S”. Jakarta: Erlangga. 1999.

[3] Tipler, P.A. "Fisika untuk Sains dan Teknik Jilid 1, terjemahan Lea Prasetio dan Rahmad W". Adi. Jakarta: Erlangga. 1998

[4] Campbell, Wallace H. "Introduction to geomagnetic fields (edisi ke-2nd)". New York: Cambridge University Press. ISBN 978-0-521-52953-2. 2003

[5] Gustara, M.Y. “Deteksi Medan Magnet Kereta Untuk Informasi Dini Sistem Pemberhentian Darurat Berbasis Mikrokontroler Arduino Uno R3 dengan Sensor Solenoid”, Skripsi, Fakultas Teknik Universitas Lampung, Bandar Lampung. 2016. 
[6] Natalia Ptitsyna, Antonio Ponzetto. "Magnetic Fields Encountered in Electric Transport: Rail Systems, Trolleybus and Cars". Published in International Symposium on Electromagnetic. DOI:10.1109/EMCEurope.2012.6396901. 2012

[7] Jein Sintia Dewi Ta'uno, Gerald H. Tamuntuan, Seni H.J. Tongkukut. "Analisis Medan Magnet Bumi Sebelum dan Sesudah Kejadian Gempa". Jurnal MIPA UNSRAT ONLINE, Vol. 5 (2), 65-69. Jurusan Fisika, FMIPA, Unsrat Manado. 2016.

[8] Teguh Prasetyo, Adey Tanauma, As'ari. "Pola Variasi Reguler Medan Magnet Bumi di Tondano". Jurnal MIPA UNSRAT ONLINE, Vol. 3 (1), 30 34. Jurusan Fisika, FMIPA, Unsrat Manado. 2014.

[9] Vincent J. Hare, John A. Tarduno, Thomas Huffman, Michael Watkeys, Phenyo C. Thebe, Munyaradzi Manyanga, Richard K. Bono and Rory D. Cottrell. "New Archeomagnetic Directional Records From Iron Age Southern Africa (ca. 425-1550 CE) and Implications for the South Atlantic Anomaly". Geophysical Research Letters. Volume 45, Issue 3. Published online Feb 15, 2018 https://doi.org/10.1002/2017GL076007

[10]Maxwell Brown, Monika Korte, Richard Holme, Ingo Wardinski, and Sydney Gunnarson. "Earth's magnetic field is probably not reversing". Proceeding of the National Academy of Sciences of the United States of America (PNAS). Volume 115 (20) 5111-5116; first published April 30, 2018 https://doi.org/10.1073/pnas.1722110115 